\title{
Electrochemical Study of Anodized Titanium in Phosphoric Acid
}

\author{
M. Khadiri $\mathbb{D}^{1},{ }^{1}$ M. Elyaagoubi, ${ }^{2}$ R. Idouhli, ${ }^{1}$ Y. Koumya $\mathbb{D}^{1},{ }^{1}$ O. Zakir, ${ }^{1}$ J. Benzakour, \\ A. Benyaich $\mathbb{D}^{1},{ }^{1}$ A. Abouelfida, ${ }^{1}$ and A. Outzourhit ${ }^{2}$ \\ ${ }^{1}$ Laboratory of Physico-Chemistry of Materials and Environment, Cadi Ayyad University, Marrakech B.P 2390, Morocco \\ ${ }^{2}$ Laboratory of Nanomaterials for Energy and Environment, Faculty of Science Semlalia, Cadi Ayyad University, \\ Marrakech B.P 2390, Morocco
}

Correspondence should be addressed to M. Khadiri; khadiri_m@gmx.fr

Received 2 March 2020; Accepted 25 April 2020; Published 12 May 2020

Academic Editor: Michelina Catauro

Copyright $(\odot 2020$ M. Khadiri et al. This is an open access article distributed under the Creative Commons Attribution License, which permits unrestricted use, distribution, and reproduction in any medium, provided the original work is properly cited.

\begin{abstract}
The anodization of the Ti-Cu (2\%) alloy was carried out in a $5 \mathrm{M} \mathrm{H}_{3} \mathrm{PO}_{4}$ solution for 2 minutes. The obtained layers are characterized by XPS, X-ray diffraction, and Raman spectroscopy. The results showed that the obtained films are composed of poorly crystallized $\mathrm{TiO}_{2}$ oxide. Electrochemical Impedance spectroscopy studies revealed that the thickness of the formed film increases with increasing anodization potential. Additionally, the resistance of charge transfer becomes higher when the anodization potential increases. Thus, the Mott Schottky model revealed that the formed film is an $n$-type semiconductor. The density of charge carriers is in good agreement with those found in the literature. Also, it is found that the flat-band potential increases with increasing treatment potential.
\end{abstract}

\section{Introduction}

Titanium and its alloy are highly solicited in many fields of use, especially in the area of medical implants [1-4]. Titanium is also used in submarines and aeronautical installations due to its physical properties and its lightness [5]. The resistance of titanium and its alloys in many acidic media makes them very useful in chemical industries [6-9]. This resistance against corrosion of titanium and its alloys is due to the formation of an oxide protective film. The nature and physical properties of the formed film depend on the mode of its formation. So, it is reported in the literature that the titanium oxide films exhibit either $p$ - or $n$-type conductivity depending on their stoichiometry and the nature of the resulting defects $[10,11]$. Titanium oxide, especially $\mathrm{TiO}_{2}$, is widely used in photocatalyst application [12].

Further, it was found that, in most acidic media, titanium oxide exhibits high resistance to corrosion, and almost no anodic activity is observed in a wide range of applied voltage. However, it can act as catalytic support for the reduction reaction with a preferential affinity to the reduction of oxygen $[13,14]$. Titanium oxide was also investigated for its electrochromic properties [15] and is widely used in photovoltaic cells [15-18] and sensors [19-21].

Titanium oxide can be obtained by several techniques such as gel sol [22], thermal oxidation [23], radiofrequency sputtering [24], electrodeposition [25], and, in particular, anodic anodization of titanium and its alloys in different acidic or basic solutions. This technique seems promising since it is inexpensive and guarantees the reproducibility of the stoichiometry of the prepared films. The electrochemical study of titanium oxides obtained by different techniques presents different and very complex electrical circuits depending on the preparation technique of the oxide films.

The objective of the present work is to prepare titanium oxide layers by anodizing Ti-Cu alloy (2\%) in phosphoric acid at different potentials. These layers will be characterized by X-ray diffraction, Raman spectroscopy, and energy dispersive X-ray spectroscopy (EDS). The oxidation state of the elements was studied by X-ray photoelectron spectroscopy. The surface morphology of the samples prepared was studied by scanning electron microscopy. The semiconductor nature of the formed films is revealed by Mott Schottky analysis, 
and an equivalent circuit was proposed by electrochemical impedance spectroscopy.

\section{Materials and Methods}

Anodization of $\mathrm{Ti}-\mathrm{Cu}(2 \%)$ alloy was carried out in twoelectrode configuration, where titanium is the anode, and a sheet of highly pure platinum with a large surface was the cathode. The surface of the titanium alloy exposed to the solutions is $1 \mathrm{~cm}^{2}$. The anodization was performed with a stabilized tension DC power supply. The range of the applied potential extended from 20 to $35 \mathrm{~V}$ in $5 \mathrm{M}$ phosphoric acid solution prepared from a $85 \%$ analytical-grade phosphoric acid.

Before anodization, the titanium samples were polished with different emery paper sizes (from 220 to 5000 grade). After, the samples were rinsed vigorously with tap water and distilled water followed by cleaning in an ultrasonic bath for 15 minutes.

After anodization, samples were characterized by X-ray diffraction to determine crystalline structures.

XPS was used to determine the oxidation states of titanium and oxygen on the surface of anodized samples. Additionally, the anodized samples were characterized by Raman spectroscopy with an excitation wavelength of $536 \mathrm{~nm}$. The morphology of the obtained films and their compositions were determined by scanning electron microscopies coupled to an EDS analyzer. Some samples are annealed in an oven for five hours at $800^{\circ} \mathrm{C}$.

Impedance spectroscopy and the capacitance measurements at a frequency of $1 \mathrm{kHz}$ were carried out using the type PZC 301 potentiostat/galvanostat in $\mathrm{Na}_{2} \mathrm{SO}_{4} \quad 10^{-1} \mathrm{M}$ solution.

\section{Results and Discussion}

The anodized samples are colored, and their colors depend on the anodization potential. We start from a red-violet color at $20 \mathrm{~V}$ that becomes dark blue at $25 \mathrm{~V}$ then turns to a pale blue color at $35 \mathrm{~V}$. The titanium alloy is coated with a colored layer after anodization. This allows broad use in the field of medical implants, given that we can know its location depending on the color of the implant [26].

During the anodization processes of samples in phosphoric acid $5 \mathrm{M}$, the evolution of the current density with time consists of a fast drop followed by stabilization at very low values close to zero, as shown in Figure 1.

It seems that the anodization time had no effect on the thickness since the composition of the film remained constant, as reported in Figure 2. Nevertheless, the thickness increased with increasing anodization voltage (Figure 3 ). These observations are in good agreement with phosphoric acid or other acidic media results reported in the literature $[27,28]$.

When the titanium content decreases, the oxygen content increases as the anodization voltage increases. This suggests that the thickness of the films formed increases with the anodization voltage. However, when the voltage is fixed, the oxygen and titanium contents remain unchanged, and

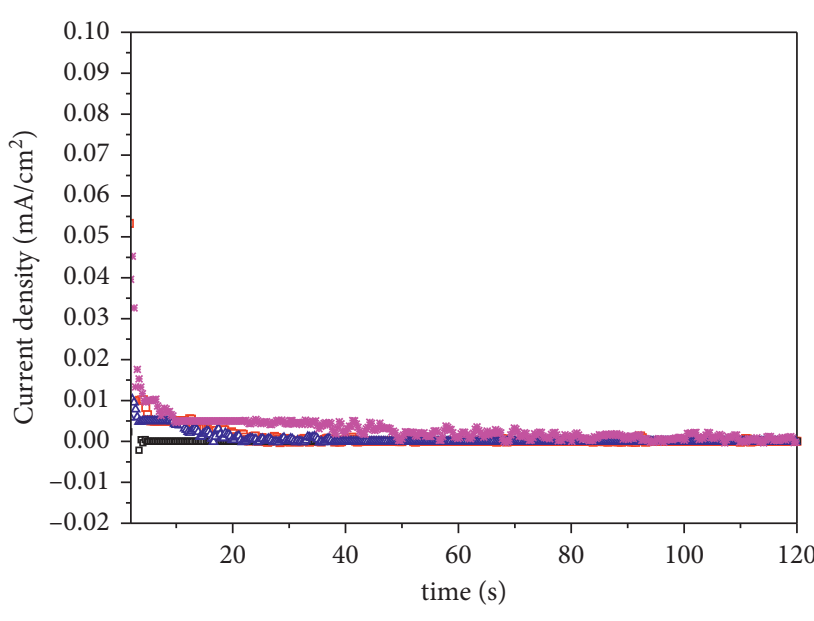

- Sample anodized at $20 \mathrm{~V}$ for $2 \mathrm{~min}$
- Sample anodized at $25 \mathrm{~V}$ for $2 \mathrm{~min}$
$\triangle$ Sample anodized at $30 \mathrm{~V}$ for $2 \mathrm{~min}$
* Sample anodized at $35 \mathrm{~V}$ for $2 \mathrm{~min}$

Figure 1: Chronoamperometric curves obtained at different applied potential during $2 \mathrm{~min}$, in $5 \mathrm{M}$ phosphoric acid.

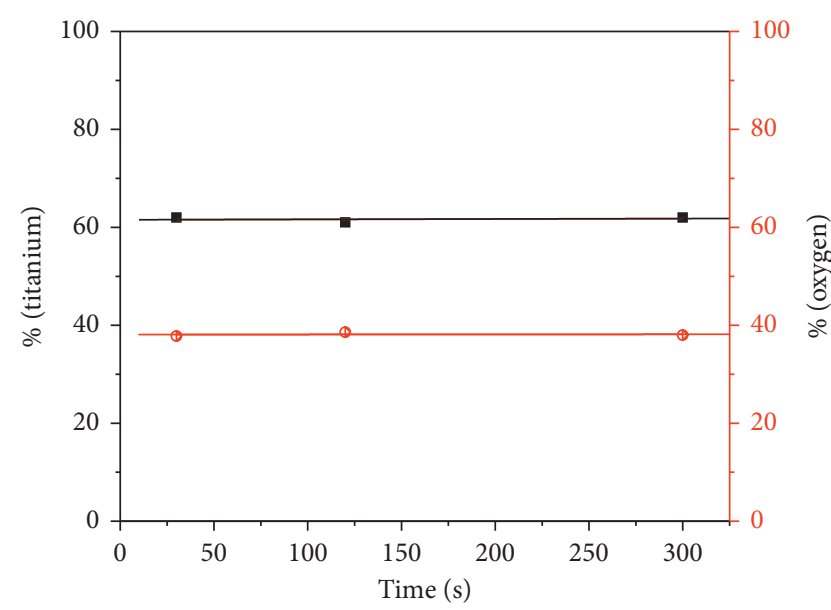

- Evolution of titanium percentage with anodisation time

- Evolution of oxygen percentage with anodisation time

FIgUre 2: Amounts of titanium and oxygen at fixed polarization voltage $(25 \mathrm{~V})$ at various times.

the color of the samples remains unchanged even if the anodization time varies.

From the diffractograms of anodized samples in phosphoric acid $5 \mathrm{M}$, the only peaks observed were attributed to titanium (file 00-001-1197). No peak characteristics of titanium oxide were observed, suggesting that the obtained oxide films are not crystallized. Further, it can be easily seen that the intensity of the Ti peaks decreases when the applied voltage increases, suggesting an increase in the thickness of the oxide films.

XPS measurements can determine the oxidation state of titanium in the formed films. Figures 5(a) and 5(b) show the Ti2p and O1s XPS peaks of the oxide films obtained from the titanium-copper alloy anodized in phosphoric acid $5 \mathrm{M}$ at $35 \mathrm{~V}$ under potentiostatic control. 


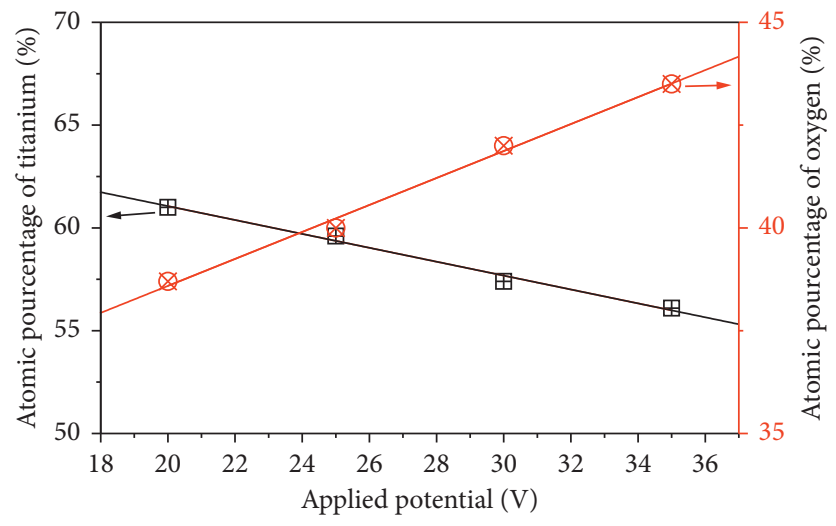

$\boxplus$ Amount of titanium

$\otimes$ Amount of oxygen

FIGURE 3: Amounts of titanium and oxygen during $2 \mathrm{~min}$ at various polarization voltages. Samples anodized at different applied voltage were characterized by X-ray diffraction. Figure 4 illustrates the results.

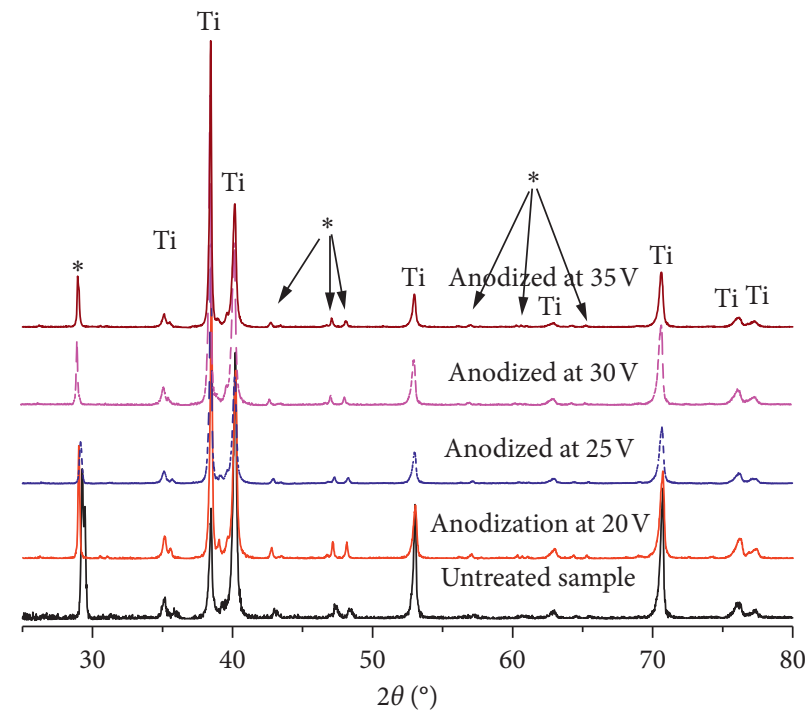

FIgURE 4: X-ray diffraction of anodized titanium in phosphoric acid $5 \mathrm{M}$ obtained at different voltages for 2 min. * Sample carrier.

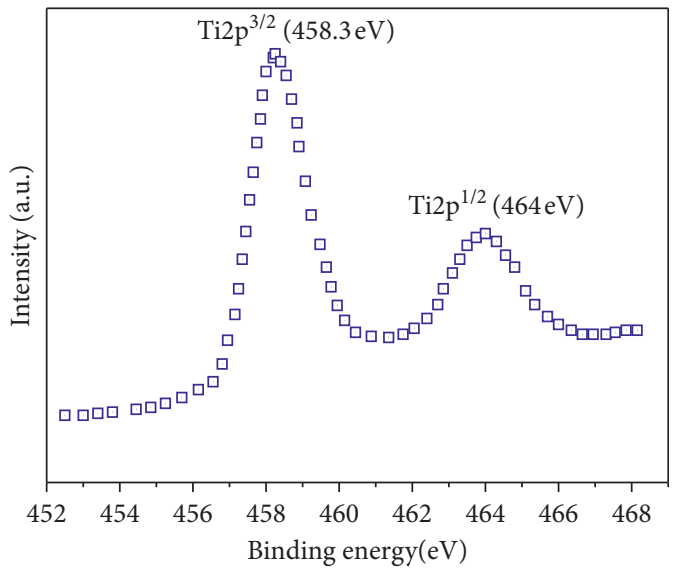

(a)

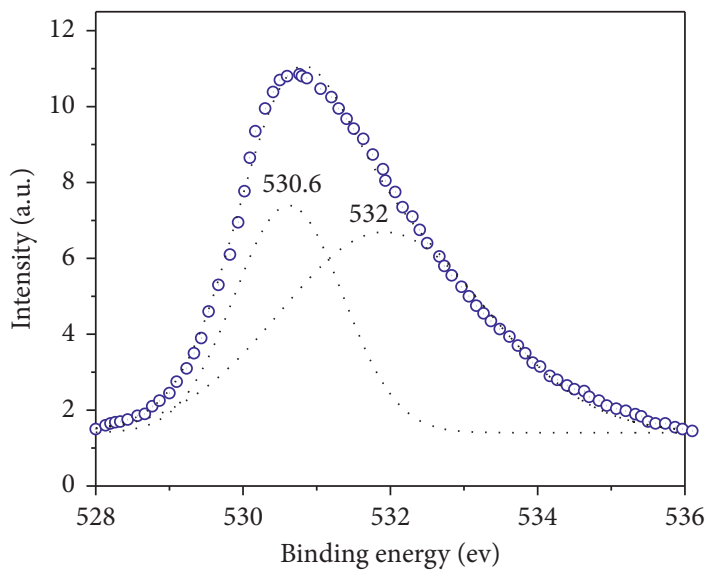

- O1s peak

(b)

FIgURE 5: Ti2p XPS spectra for titanium anodized at $35 \mathrm{~V}$ for $2 \mathrm{~min}$ in $5 \mathrm{M}$ phosphoric acid. (a) Ti2p spectra; (b) O1s spectra. 


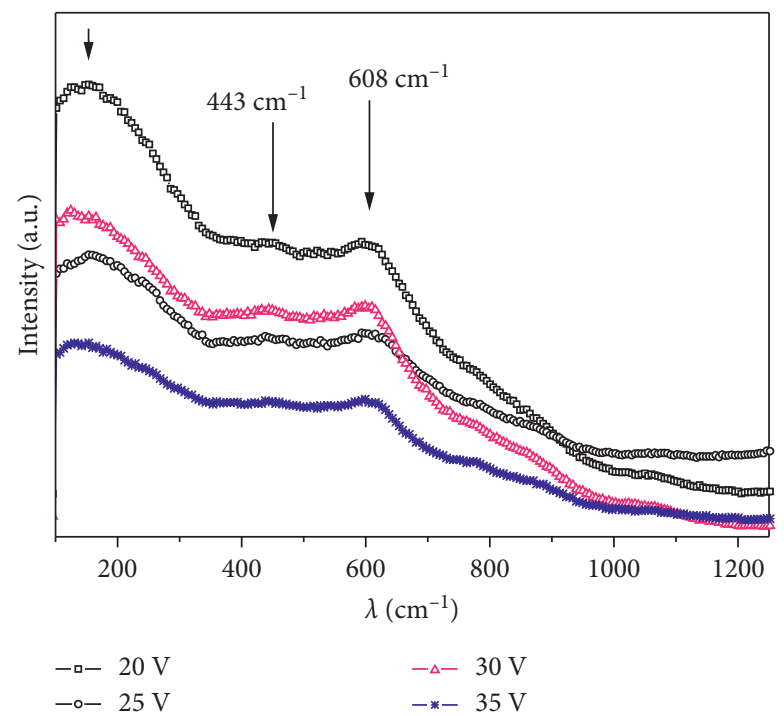

Figure 6: Raman spectra of different anodized samples at different voltages in $\mathrm{H}_{3} \mathrm{PO}_{4} 5 \mathrm{M}$.

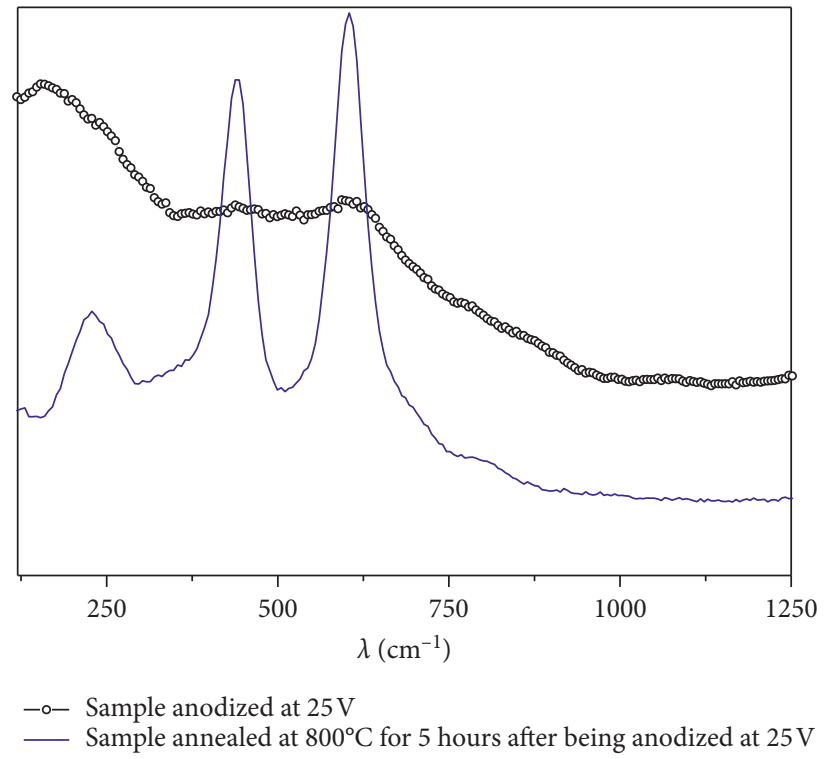

Figure 7: Raman spectra obtained for anodized sample at $25 \mathrm{~V}$ before and after annealing at $800^{\circ} \mathrm{C}$ for 5 hours.

The Ti2 $\mathrm{p}^{3 / 2}$ peak is centered at $458.36 \mathrm{eV}$. Its width at half height is $1.56 \mathrm{eV}$. These values show that the titanium is at oxidation state 4 . These characteristics are consistent with those of titanium in $\mathrm{TiO}_{2}$. Furthermore, the difference between the energy of Ti2 $\mathrm{p}^{3 / 2}$ and Ti2 $\mathrm{p}^{1 / 2}$ is around $5.7 \mathrm{eV}$. This value is characteristic of oxygen bond titanium in the $\mathrm{TiO}_{2}$ oxide type $[29,30]$.

The oxygen peak, shown in Figure 5(b), is large and can be deconvoluted to at least two subpeaks, centered at $530.6 \mathrm{eV}$ and $532 \mathrm{eV}$. The first peak is attributed to the oxygen engaged in a Ti-O bond in $\mathrm{TiO}_{2}$, and the second corresponds either to oxygen bound to water or adsorbed oxygen type $\mathrm{O}_{2}[31,32]$. Indeed, a strong release of oxygen was observed during the anodization.
Figure 6 shows the Raman spectra of samples anodized at different voltages in $5 \mathrm{M} \mathrm{H}_{3} \mathrm{PO}_{4}$. We note the presence of two visible bands: the first is centered at $443 \mathrm{~cm}^{-1}$ and the other is centered at $608 \mathrm{~cm}^{-1}$. This is in addition to a weaker, wider, and less pronounced band at $160 \mathrm{~cm}^{-1}$.

To be able to attribute the different observed bands, we performed Raman analysis on the same samples after having been annealed at $800^{\circ} \mathrm{C}$ for 5 hours. Figure 7 shows the obtained spectrum for the sample anodized at $25 \mathrm{~V}$.

The bands observed for the annealed sample (blue line) correspond to those of the rutile phase of $\mathrm{TiO}_{2}$. This is further confirmed by the X-ray diffraction spectrum of the anodized samples, which has been annealed for 5 hours at 


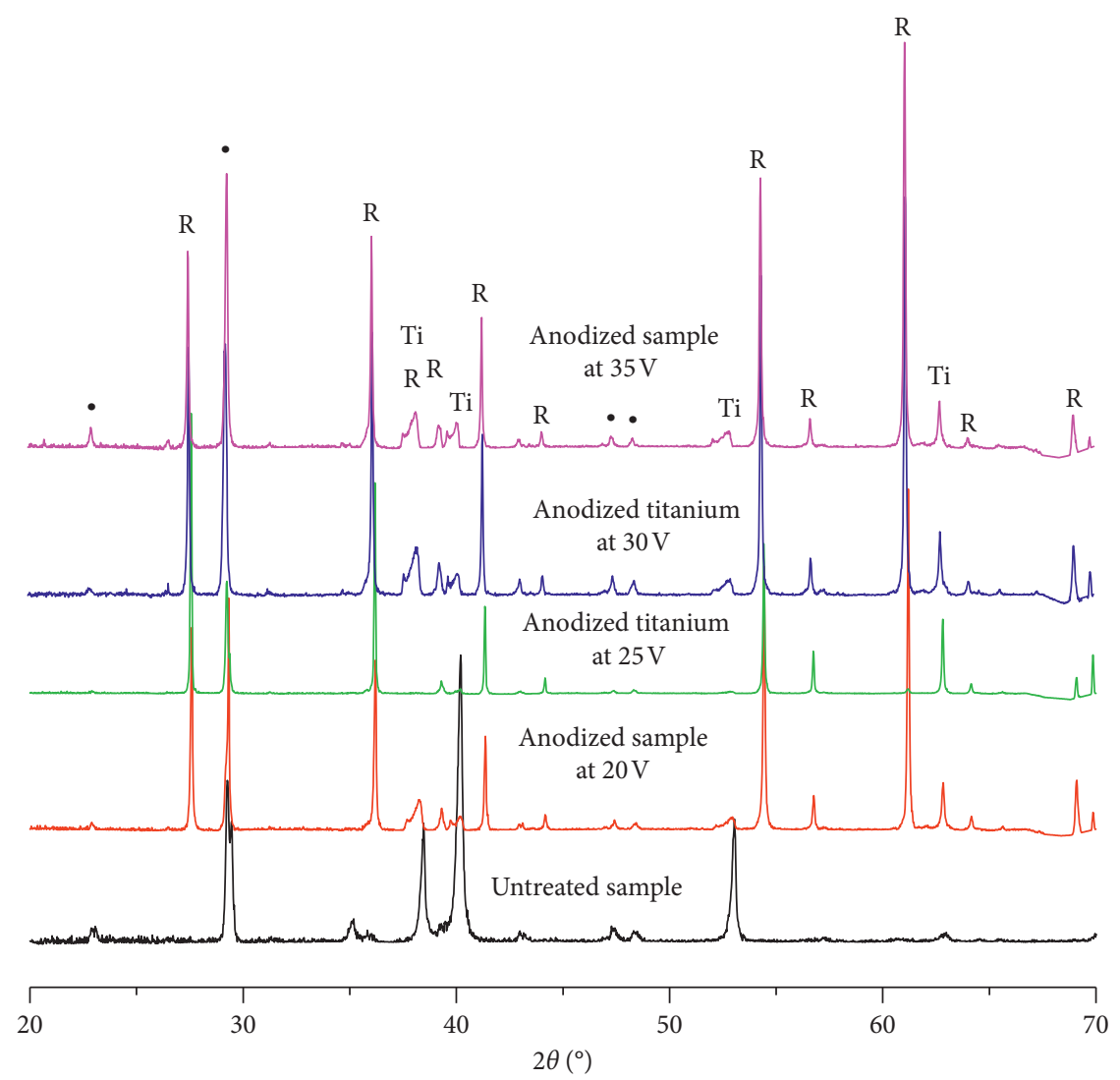

Figure 8: X-ray diffraction of anodized samples annealed at $800^{\circ} \mathrm{C}$ for 5 Hours. $\bullet$ : Simple careers; Ti: titanium; R: rutile.

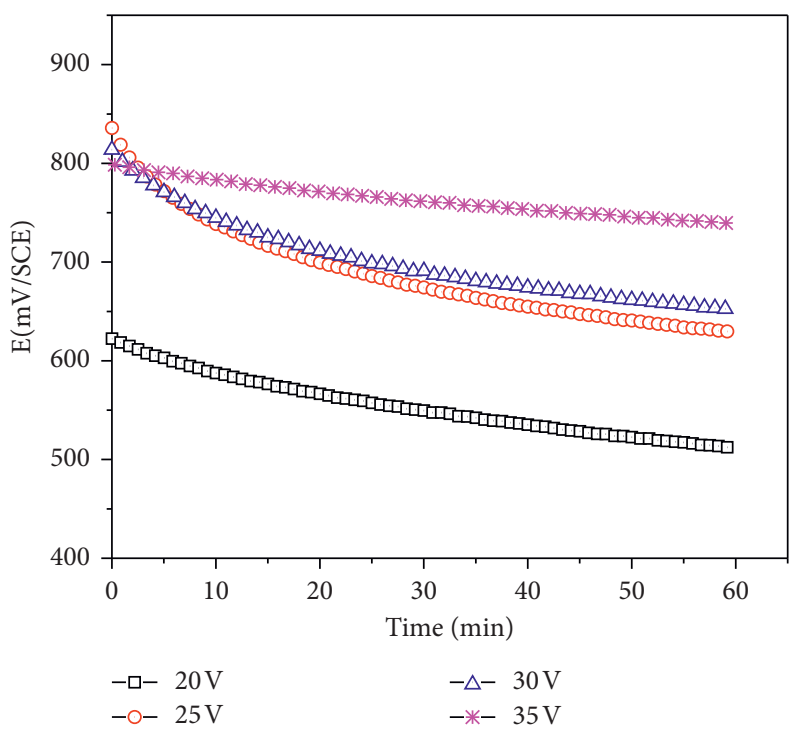

FIGURE 9: Open-circuit potential against time in $0.1 \mathrm{M} \mathrm{Na}_{2} \mathrm{SO}_{4}$.

$80^{\circ} \mathrm{C}$ (Figure 8 ); it clearly shows that annealed films consist mainly of rutile $\mathrm{TiO}_{2}$ phase.

According to the literature, the bands appearing on the Raman spectrum (Figures 6 and 7) may be allocated as follows.
The band at $443 \mathrm{~cm}^{-1}$ corresponds to the Eg mode of the $\mathrm{TiO}_{2}$ rutile, while the one centered at $608 \mathrm{~cm}^{-1}$ corresponds to the Alg mode of the $\mathrm{TiO}_{2}$ rutile [33].

Other studies have suggested that the band observed at $146 \mathrm{~cm}^{-1}$ is relative to the B1g mode of rutile [34-39]. 


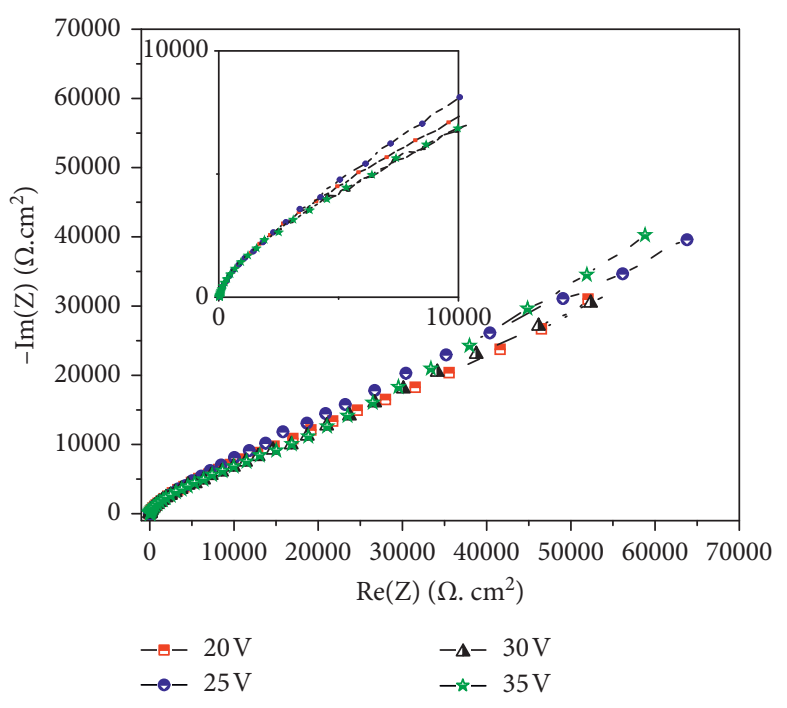

(a)

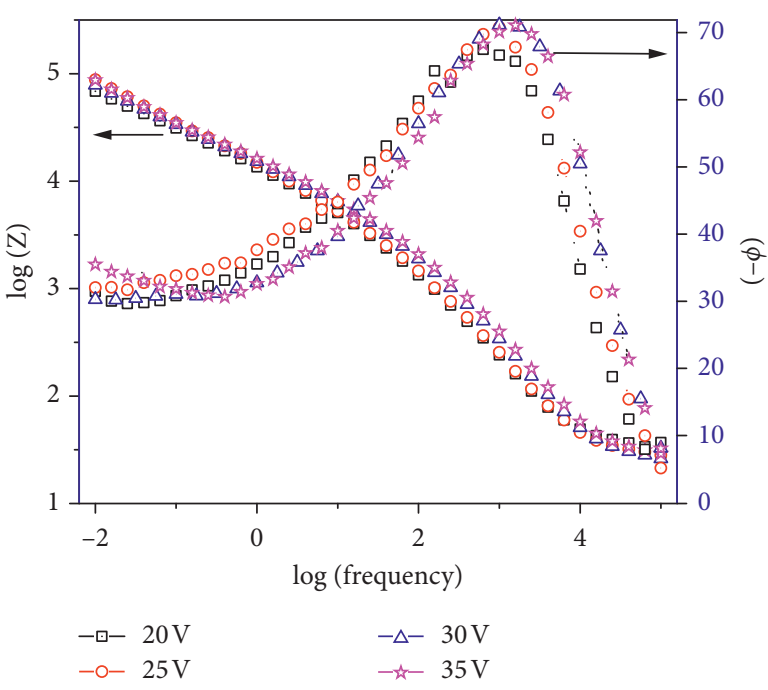

(b)

Figure 10: Electrochemical impedance spectroscopy of anodized samples, obtained in $10^{-1} \mathrm{M}$ of $\mathrm{Na}_{2} \mathrm{SO}_{4}$ at OCP. ((a) Nyquist representation; (b) Bode representation).

However, other studies attribute this band to the anatase phase [40].

From the above, it can be concluded that, during anodization, a poorly crystallized rutile $\mathrm{TiO}_{2}$ is formed.

After anodization of the samples in $5 \mathrm{M}$ phosphoric acid, we recorded the evolution of the open-circuit potential as a function of time in $0.1 \mathrm{M}$ of $\mathrm{Na}_{2} \mathrm{SO}_{4}$. As shown in Figure 9, we can note that the potential stabilizes at a noble value with increasing anodization potential and also protects the titanium surface alloy against corrosion better. After one hour, the potential tries to be fixed and we can subsequently perform Nyquist and Bode plots.

The Nyquist and Bode representations of the impedance spectra of the anodized Ti-Cu alloy (2\%) at different voltages in $\mathrm{H}_{3} \mathrm{PO}_{4} 5 \mathrm{M}$ for $2 \mathrm{~min}$, obtained in $10^{-1} \mathrm{M}$ of $\mathrm{Na}_{2} \mathrm{SO}_{4}$ at open-circuit potential (OCP), are, respectively, shown in Figures 10(a) and 10(b).

From Nyquist representation, and as shown in Figure 10(a) inset, it can be concluded that there are no masked phenomena at high frequency.

The Bode representation, as presented in Figure 10(b), shows that the interfacial process is the same for all studied samples. Moreover, the observed phase shift is negative, suggesting a capacitive behavior of the equivalent electrical circuit. The peak observed at high frequency suggests the presence of a constant phase element (CPE) since the phase shift does not reach $-90(\approx-70 \mathrm{rad})$. The existence of masked phenomena at low frequency cannot be excluded since the phase shift at low frequency (between $100 \mathrm{MHz}$ and $1 \mathrm{~Hz}$ ) is different from zero, and there is a small shoulder when log (frequency) is equal to -0.5 .

The plot of $Z$ Modulus as a function of the logarithm of the frequency shows the presence of two straight line segments with slopes $\alpha_{1}$ and $\alpha_{2}$ (Figure 11). The values of these parameters are regrouped in Table 1.
It can be observed that both parameters are less than one, while the values of $\alpha_{1}$ are close to 0.5 . This suggests that the equivalent circuit may include two CPEs with the presence of a Warburg diffusion regime $(W)$ [41].

Indeed, the equivalent circuit capable of fitting the experimental curves $(-\mathrm{imZ}=f(\operatorname{ReZ}))$, with an acceptable correlation coefficient, is given in Figure 12.

In this diagram, $R_{\mathrm{s}}$ is the solution resistance, $R_{\mathrm{f}}$ is the resistance of the formed films, and $R_{\mathrm{dt}}$ is the charge transfer resistance. Moreover, $\mathrm{CPE}_{\mathrm{f}}$ is the constant phase element relative to the formed films, $\mathrm{CPE}_{\mathrm{dl}}$ is the constant phase element relative to the charge transfer, and $\mathrm{W}$ is the Warburg impedance.

The surface roughness of the samples may account for the CPE in the electrical equivalent circuit. Indeed, the SEM micrographs (Figure 13) of a sample polished by emery paper show a rough surface, which leads to distributed elements and consequently to a nonideal capacity.

The experimental curve and the best fit obtained by this equivalent circuit are presented in Figure 14.

Figure 14 illustrates that there is good agreement between the theoretical and experimental curves. Additionally, we note that the metal/oxide/solution interface remains the same in the range of applied potential. Furthermore, the fitting parameters grouped in Table 2 further support the conclusions derived from the Bode representation. Using Mansfield law, we get

$$
\mathrm{Ci}=\left(\mathrm{Qi} \times R_{i}^{1-\alpha}\right)^{1 / \alpha} \text {. }
$$

We have determined the film capacitance $C_{\mathrm{f}}$ and the capacitance of the double layer $C_{\mathrm{ct}}$.

The thickness $d$ of the films is obtained from the relation $C=\varepsilon \varepsilon_{0} / d S$, where $\varepsilon$ is the relative permittivity of the formed film, $\varepsilon o$ is the absolute permittivity of the vacuum, and $S$ is the surface area of the film. 


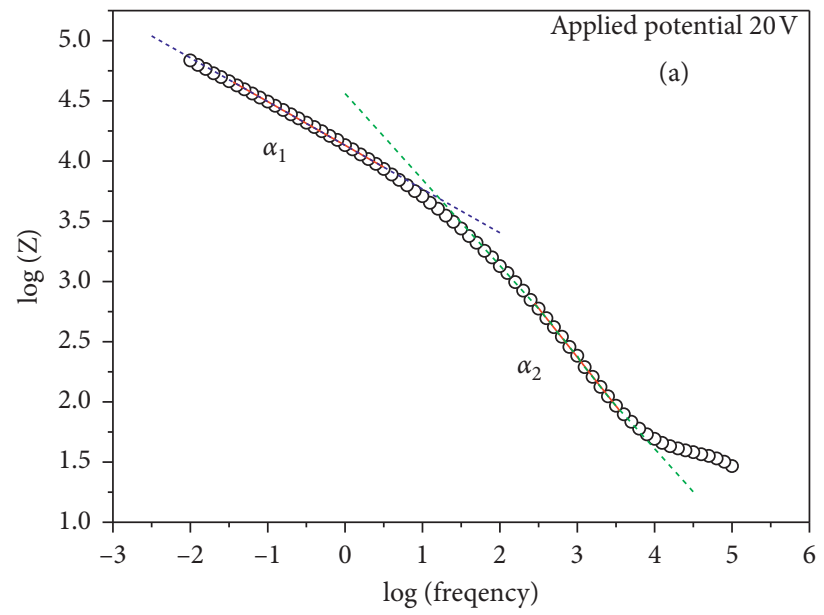

Figure 11: $\log (z)$ against $\log$ (frequency) for sample anodized at $20 \mathrm{~V}$ in $5 \mathrm{M}$ phosphoric acid.

TABLE 1: $\alpha_{1}$ and $\alpha_{2}$ values resorted from slopes of $\log (\mathrm{z})$ against $\log$ (frequency) at different anodization voltages.

\begin{tabular}{lllll}
\hline Anodization voltage & $20 \mathrm{~V}$ & $25 \mathrm{~V}$ & $30 \mathrm{~V}$ & \\
\hline$\alpha 1$ & 0.36 & 0.40 & 0.35 & 0.35 \\
$\alpha 2$ & 0.81 & 0.80 & 0.84 & 0.83 \\
\hline
\end{tabular}

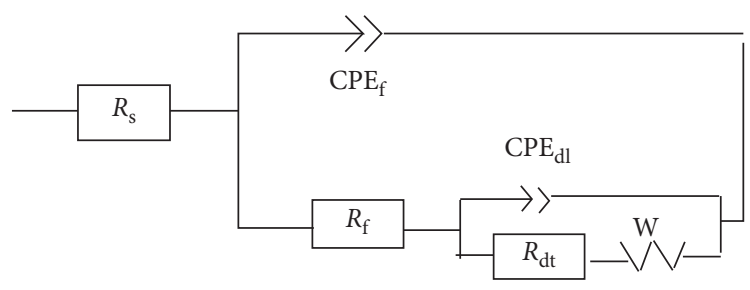

Figure 12: Electrical equivalent circuit for the as-anodized $\mathrm{Ti}-\mathrm{Cu}(2 \%)$ alloy.

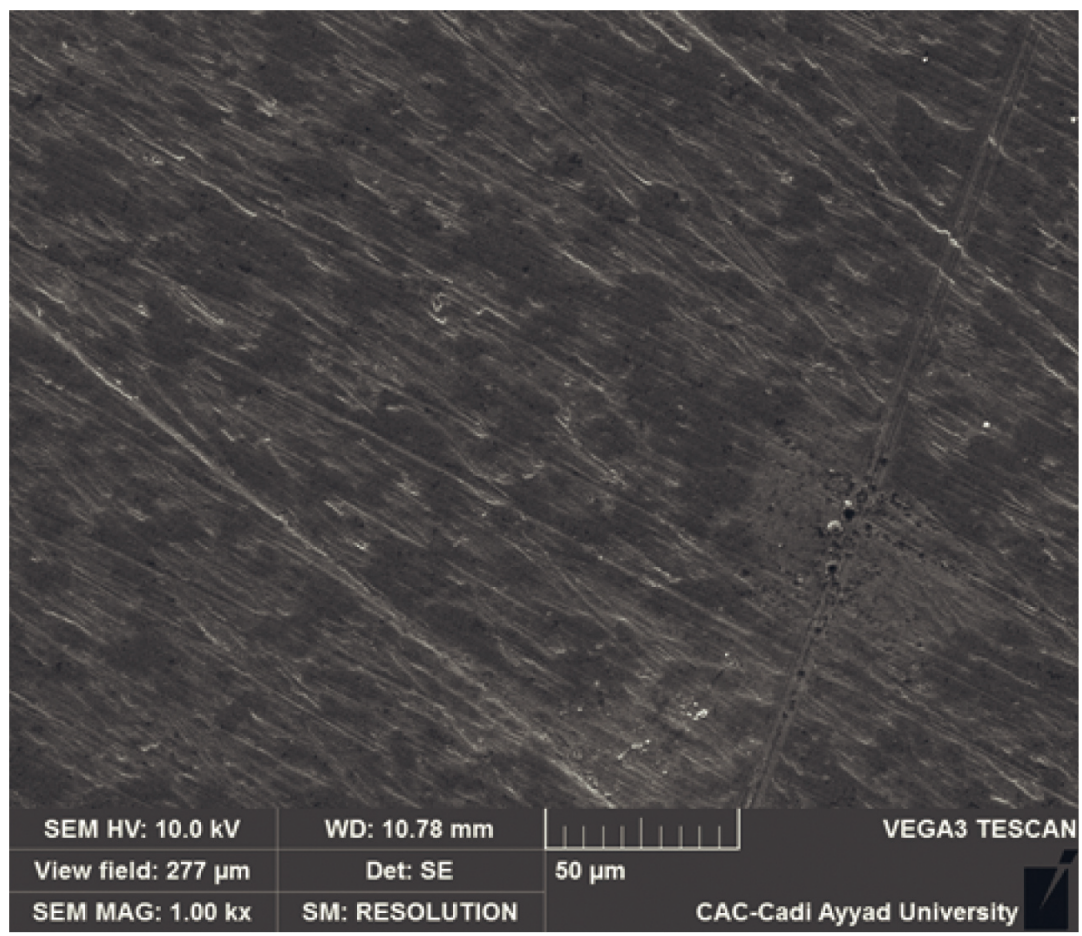

FIgURE 13: Micrograph of Ti-Cu (2\%) freshly polished with emery paper (until 5000 grade). 


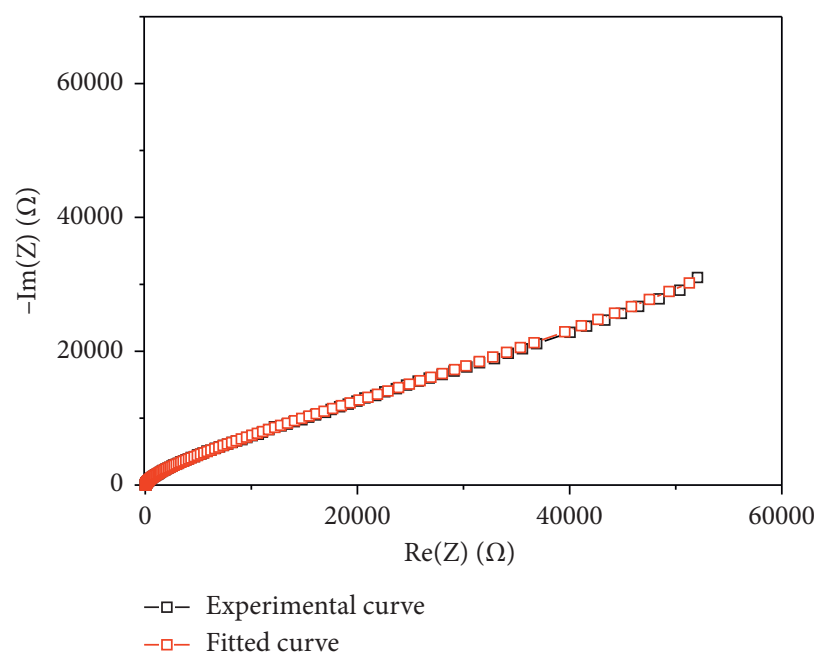

Figure 14: Nyquist representation and the best fit for the sample anodized at $30 \mathrm{~V}$ in $5 \mathrm{M}$ phosphoric acid. The parameters from the best fits are given in Table 2 .

TABLE 2: Electrochemical parameters for the electrical equivalent circuit obtained in $\mathrm{Na}_{2} \mathrm{SO}_{4} 0.1 \mathrm{M}$

\begin{tabular}{|c|c|c|c|c|c|c|c|c|c|c|c|}
\hline$(\mathrm{V})$ & $\chi \times 10^{3}$ & $\begin{array}{l}R_{1} \\
(\Omega) \\
\end{array}$ & $\begin{array}{c}Q_{f} \times 10^{6} \\
\left(\mathrm{~F} \times \mathrm{cm}^{-2}\right) \\
\end{array}$ & $\begin{array}{c}a_{1} \\
(\alpha 2) \\
\end{array}$ & $\begin{array}{c}C_{f} \times 10^{6} \\
\left(\mathrm{~F} \times \mathrm{cm}^{-2}\right) \\
\end{array}$ & $\begin{array}{l}R_{\mathrm{f}} \\
(\Omega) \\
\end{array}$ & $\begin{array}{c}Q_{\mathrm{dl}} \times 10^{6} \\
\left(\mathrm{~F} \times \mathrm{cm}^{-2}\right) \\
\end{array}$ & $\begin{array}{c}a_{2} \\
(\alpha 1) \\
\end{array}$ & $\begin{array}{r}C_{d l} \times 10^{6} \\
\left(\mathrm{~F} \times \mathrm{cm}^{-2}\right) \\
\end{array}$ & $\begin{array}{l}R_{\mathrm{ct}} \\
(\Omega) \\
\end{array}$ & $\mathrm{S}_{3}\left(\Omega \times \mathrm{s}^{-1 / 2}\right)$ \\
\hline 20 & 25 & 35.33 & 1.28 & 0.92 & 0.6 & 745 & 29.80 & 0.42 & 132 & 101165 & 15011 \\
\hline 25 & 50 & 30.07 & 1.22 & 0.90 & 0.58 & 1042 & 28.28 & 0.40 & 258 & 154531 & 23354 \\
\hline 30 & 36 & 27.43 & 0.75 & 0.94 & 0.46 & 779 & 29.88 & 0.38 & 365 & 155282 & 36812 \\
\hline 35 & 24 & 30.03 & 0.6 & 0.94 & 0.33 & 726 & 29.1 & 0.38 & 359 & 160000 & 61223 \\
\hline
\end{tabular}

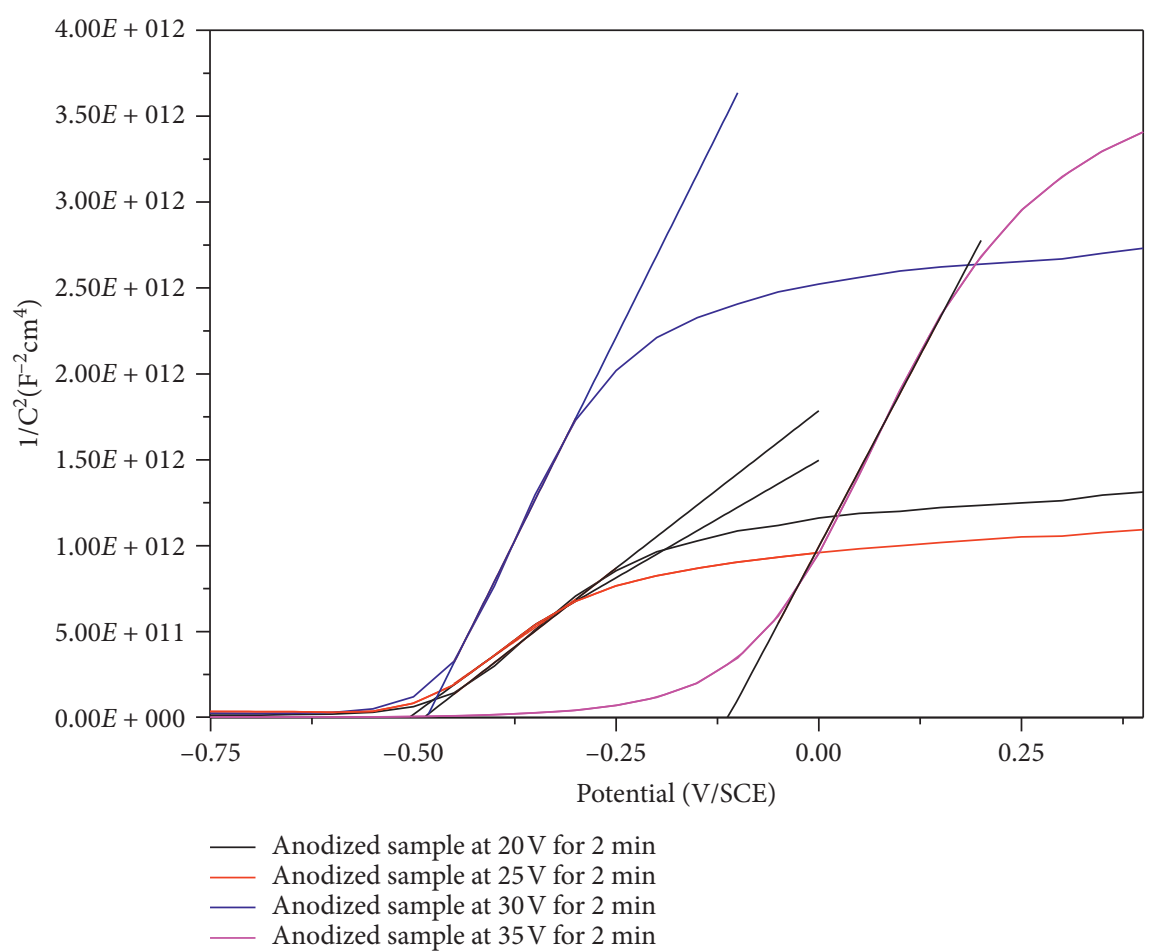

FIgURE 15: Mott-Schottky curve obtained at $1 \mathrm{KHz}$, in $0.1 \mathrm{M}$ of $\mathrm{Na}_{2} \mathrm{SO}_{4}$ sample anodized in phosphoric acid. 
TABLE 3: Electrical parameters of titanium oxide.

\begin{tabular}{lcccc}
\hline Applied potential & $20 \mathrm{~V}$ & $25 \mathrm{~V}$ & $30 \mathrm{~V}$ & $35 \mathrm{~V}$ \\
\hline $\mathrm{Nd}\left(\times 10^{18} \mathrm{~cm}^{-3}\right)$ & 1.31 & 1.44 & 1.96 & 5.28 \\
$\mathrm{E}_{\mathrm{fb}}(\mathrm{V})$ & -0.47 & -0.42 & -0.39 & -0.12 \\
\hline
\end{tabular}

From Table 2, we can say that increasing anodization potential results in a decrease in the capacitance of the formed film and, consequently, to an increase in the thickness of the formed films.

Previous studies [42] have shown that the thickness $(d)$ of the films obtained by anodizing titanium in $\mathrm{H}_{3} \mathrm{PO}_{4}$ varies linearly as a function of the anodizing voltage ( $\mathrm{Va}$ ) according to the following equation:

$$
d=1.94 \times V a+5.2(\mathrm{~nm})
$$

To have this order of magnitude, we must choose a dielectric constant value of around 30 for the formed films. This value has been reported in the literature for $\mathrm{TiO}_{2}$ films from anodized titanium samples in aqueous media [20,43].

It is important to note that the capacity of the double layer is at least 300 times greater than that of the formed film. Consequently, the Mott Schottky plot of $1 / c^{2}$ as a function of $V$ at constant frequency is relative to film capacitance.

To determine the charge carrier density $N_{\mathrm{d}}$, we used the following expression:

$$
\frac{1}{C^{2}}=\frac{2}{\varepsilon \varepsilon_{0} e N_{d}}\left(E-E_{\mathrm{fb}}+\frac{\mathrm{KT}}{e}\right)
$$

where $\varepsilon r$ is the dielectric constant of the film, $\varepsilon_{0}$ is the vacuum permittivity $\left(8.854 \times 10^{-14} \mathrm{~F} \mathrm{~cm}^{-1}\right), e$ is the elementary charge, $E_{\mathrm{fb}}$ is the flat-band potential, $K$ is the Boltzmann constant $\left(1.38 \times 10^{-23} \mathrm{~J} / \mathrm{K}\right)$, and $\mathrm{T}$ is the absolute temperature.

In Figure 15, we present the evolution of $1 / c^{2}$ against potential in $\mathrm{Na}_{2} \mathrm{SO}_{4} 0.1 \mathrm{~N}$ at a frequency of $1 \mathrm{kHz}$. The curves have two inflection points, between which a large linear increase of $1 / c^{2}$ as a function of the potential $E$ was observed. The slope of these lines is positive, indicating that the formed oxide $\mathrm{TiO}_{2}$ is an $n$-type semiconductor. The slope of this line permits us to determine the values of charge carrier density $\mathrm{Nd}$ and the flat-band potential, which are summarized in Table 3 as a function of the anodization voltage.

The increase of the charge carrier density with the anodization voltage can be related to the nature of defects of the oxide formed during anodization as summarized in Table 3. Additionally, the flat-band potential decreases as a function of the anodizing voltage; this is in perfect agreement with the increase of charge carrier numbers (i.e., a decrease in band bending).

\section{Conclusion}

Samples of titanium copper (2\%) alloy were anodized in $5 \mathrm{M}$ phosphoric acid under potential control. The range of applied potential was extended from 20 to $35 \mathrm{~V}$ with a twoelectrode configuration. The obtained anodized samples were colored and easily distinguishable depending on their anodized potential. The chronoamperometric curves recorded during the anodization process showed an abrupt drop of the current with time due to the formation of a protective layer.

It is found that the thickness of the formed films increased with increasing anodizing potential. The formed films consisted of a poorly crystallized rutile $\mathrm{TiO}_{2}$, as shown by Raman, X-ray diffraction, and XPS and EDX measurements.

The electrochemical impedance spectra obtained in $0.1 \mathrm{M}$ of $\mathrm{Na}_{2} \mathrm{SO}_{4}$, for the anodized samples showed that the charge transfer resistance increased with increasing applied potential. In addition, it was found from the electrochemical impedance study that the thickness of the formed film increases with increasing applied potential and that the relative permittivity of the formed oxide is approximately 30 . The formed film is an $n$-type semiconductor, and the charge carrier density is in the range of $10^{18} \mathrm{~cm}^{-3}$.

\section{Data Availability}

The data used to support the findings of this study are available from the corresponding author upon request.

\section{Conflicts of Interest}

The authors declare that they have no conflicts of interest regarding the publication of this paper.

\section{Acknowledgments}

The authors are grateful to the Center of Analyses and Characterization (CAC) of University Cadi Ayyad, Marrakech, Morocco.

\section{Supplementary Materials}

The graphical abstract resume different techniques used in the present work. We used the anodization technique for obtaining oxide films under potential control, with two electrode devices. Obviously, the current density was also recorded. The obtained film was characterized before annealing and after being annealed with different characterization techniques such as X-ray diffraction, XPS, Raman shift, and also scanning electron microscopy coupled to EDS (right side of the graphical abstract). The nonannealed samples were studied for electrochemical properties by performing EIS and Mott-Schottky measurements (left side of the graphical abstract). (Supplementary Materials)

\section{References}

[1] A. E. F. Pontes, C. T. De Toledo, V. G. Garcia, F. S. Ribeiro, and C. E. Sakakura, "Torque analysis of a triple acid-etched titanium implant surface," The Scientific World Journal, vol. 2015, Article ID 819879, 3 pages, 2015.

[2] R. Van Noort, "Titanium: the implant material of today," Journal of Materials Science, vol. 22, no. 11, pp. 3801-3811, 1987. 
[3] K.-H. Frosch and K. M. Stürmer, "Metallic biomaterials in skeletal repair," European Journal of Trauma, vol. 32, no. 2, pp. 149-159, 2006.

[4] L. Benea, E. Mardare-Danaila, M. Mardare, and J.-P. Celis, "Preparation of titanium oxide and hydroxyapatite on Ti-6Al$4 \mathrm{~V}$ alloy surface and electrochemical behaviour in bio-simulated fluid solution," Corrosion Science, vol. 80, pp. 331-338, 2014.

[5] A. W. E. Hodgson, Y. Mueller, D. Forster, and S. Virtanen, "Electrochemical characterisation of passive films on Ti alloys under simulated biological conditions," Electrochimica Acta, vol. 47, no. 12, pp. 1913-1923, 2002.

[6] R. Souto, M. M. Laz, and R. L. Reis, "Degradation characteristics of hydroxyapatite coatings on orthopaedic TiAlV in simulated physiological media investigated by electrochemical impedance spectroscopy," Biomaterials, vol. 24, no. 23, pp. 4213-4221, 2003.

[7] J. E. G. González and J. C. Mirza-Rosca, "Study of the corrosion behavior of titanium and some of its alloys for biomedical and dental implant applications," Journal of Electroanalytical Chemistry, vol. 471, no. 2, pp. 109-115, 1999.

[8] M. E. Khadiri, A. Benyaïch, A. Outzourhit, and E. L. Ameziane, "Etude de la corrosion de l'alliage Ti-Cu (2\%) dans l'acide phosphorique," Annales de Chimie-Science des Matériaux, vol. 25, pp. 447-455, 2000.

[9] M. E. Khadiri, A. Benyaïch, A. Outzourhit, and E. H. L. Ameziane, "Etude de la reactivite de l'alliage Ti-Cu (2\%) traite a differentes tensions dans H3PO4 5M," Annales de Chimie-Science des Matériaux, vol. 27, pp. 33-42, 2002.

[10] M. K. Nowotny, P. Bogdanoff, T. Dittrich, S. Fiechter, A. Fujishima, and H. Tributsch, "Observations of p-type semiconductivity in titanium dioxide at room temperature," Materials Letters, vol. 64, no. 8, pp. 928-930, 2010.

[11] B. J. Morgan and G. W. Watson, "Intrinsic n-type defect formation in TiO2: a comparison of rutile and anatase from GGA+U calculations," The Journal of Physical Chemistry C, vol. 114 , no. 5, pp. 2321-2328, 2010.

[12] M. Lazar, S. Varghese, and S. Nair, "Photocatalytic water treatment by titanium dioxide: recent updates," Catalysts, vol. 2, no. 4, pp. 572-601, 2012.

[13] I. M. Al-Akraa, T. Ohsaka, and A. M. Mohammad, "A promising amendment for water splitters: boosted oxygen evolution at a platinum, titanium oxide and manganese oxide hybrid catalyst," Arabian Journal of Chemistry, vol. 12, no. 7, pp. 897-907, 2019.

[14] M. Vezvaie, J. J. Noël, Z. Tun, and D. W. Shoesmith, "Hydrogen absorption into titanium under athodic polarization: an in-situ neutron reflectometry and EIS study," Journal of The Electrochemical Society, vol. 160, no. 9, pp. C414-C422, 2013.

[15] J. Löberg, J. Perez Holmberg, I. Mattisson, A. Arvidsson, and E. Ahlberg, "Electronic properties ofTiO2Nanoparticles films and the effect on apatite-forming ability," International Journal of Dentistry, vol. 2013, pp. 1-14, 2013.

[16] M. Grätzel, "Photoelectrochemical cells," in Mater. Sustain. Energy, pp. 26-32, Co-Published with Macmillan Publishers Ltd, New York, NY, USA, 2010.

[17] M. Grätzel, "Conversion of sunlight to electric power by nanocrystalline dye-sensitized solar cells," Journal of Photochemistry and Photobiology A: Chemistry, vol. 164, no. 1-3, pp. 3-14, 2004.

[18] H. He, C. Liu, K. D. Dubois, T. Jin, M. E. Louis, and G. Li, "Enhanced charge separation in nanostructured $\mathrm{TiO} 2$ materials for photocatalytic and photovoltaic applications,"
Industrial \& Engineering Chemistry Research, vol. 51, no. 37, pp. 11841-11849, 2012.

[19] K. Zakrzewska, "Gas sensing mechanism of TiO2-based thin films," Vacuum, vol. 74, no. 2, pp. 335-338, 2004.

[20] I. J. Gomez, B. Arnaiz, M. Cacioppo, F. Arcudi, and M. Prato, "Nitrogen-doped Carbon Nanodots for bioimaging and delivery of paclitaxel," Journal of Materials Chemistry B, vol. 6, pp. 1-3, 2018.

[21] J. Lee, D. H. Kim, S.-H. Hong, and J. Y. Jho, “A hydrogen gas sensor employing vertically aligned $\mathrm{TiO} 2$ nanotube arrays prepared by template-assisted method," Sensors and Actuators B: Chemical, vol. 160, no. 1, pp. 1494-1498, 2011.

[22] M. J. Alam and D. C. Cameron, "Preparation and characterization of $\mathrm{TiO} 2$ thin films by sol-gel method," Journal of Sol-Gel Science and Technology, vol. 25, no. 2, pp. 137-145, 2002.

[23] M. V. Diamanti, S. Codeluppi, A. Cordioli, and M. P. Pedeferri, "Effect of thermal oxidation on titanium oxides' characteristics," Journal of Experimental Nanoscience, vol. 4, no. 4, pp. 365-372, 2009.

[24] P. Löbl, M. Huppertz, and D. Mergel, "Nucleation and growth in TiO2 films prepared by sputtering and evaporation," Thin Solid Films, vol. 251, no. 1, pp. 72-79, 1994.

[25] P. M. Dziewoński and M. Grzeszczuk, "Deposition of thin $\mathrm{TiO} 2$ layers on platinum by means of cyclic voltammetry of selected complex Ti (IV) media leading to anatase," Electrochimica Acta, vol. 54, pp. 4045-4055, 2009.

[26] G. Yang, D. Ma, L. Liu, J. Rong, and X. Yu, "Electrochemical behavior analyses of anodic oxide film obtained on TA2 pure titanium in sulfuric acid electrolyte," Chemical Engineering Transactions, vol. 59, pp. 157-162, 2017.

[27] N. R. Armstrong and R. K. Quinn, "Auger and X-ray photoelectron spectroscopic and electrochemical characterization of titanium thin film electrodes," Surface Science, vol. 67, no. 2, pp. 451-468, 1977.

[28] M. E. Sibert, "Electrochemical oxidation of titanium surfaces," Journal of The Electrochemical Society, vol. 110, no. 1, p. 65, 1963.

[29] P. Georgios and S. M. Wolfgang, "X-ray photoelectron spectroscopy of anatase-TiO2 coated carbon nanotubes," Solid State Phenomena, vol. 162, pp. 163-177, 2010.

[30] Y. Ohashi, N. Nagatsuka, S. Ogura, and K. Fukutani, "Hydrogen distribution and electronic structure of $\mathrm{TiO} 2(110)$ hydrogenated with low-energy hydrogen ions," The Journal of Physical Chemistry C, vol. 123, no. 16, pp. 10319-10324, 2019.

[31] D. Zhang, J. Gong, J. Ma, G. Han, and Z. Tong, "A facile method for synthesis of $\mathrm{N}$-doped $\mathrm{ZnO}$ mesoporous nanospheres and enhanced photocatalytic activity," Dalton Transactions, vol. 42, no. 47, pp. 16556-16561, 2013.

[32] R. Lu, C. Wang, X. Wang et al., "Effects of hydrogenated TiO2 nanotube arrays on protein adsorption and compatibility with osteoblast-like cells," International Journal of Nanomedicine, vol. 13, pp. 2037-2049, 2018.

[33] R. L. Farrow, P. L. Mattern, and A. S. Nagelberg, "Characterization of surface oxides by Raman spectroscopy," Applied Physics Letters, vol. 36, no. 3, pp. 212-214, 1980.

[34] J. Yang, H. Ma, B. Lu, and G. Ma, "Raman spectroscopy study of phase transformation of $\mathrm{TiO} 2$ rutile single crystal induced by infrared femtosecond laser," Guangxue Xuebao/Acta Optica Sinica, vol. 27, pp. 1909-1912, 2007.

[35] H. Berger, H. Tang, and F. Lévy, "Growth and Raman spectroscopic characterization of $\mathrm{TiO} 2$ anatase single crystals," Journal of Crystal Growth, vol. 130, no. 1-2, pp. 108-112, 1993. 
[36] T. Mazza, E. Barborini, P. Piseri et al., "Raman spectroscopy characterization of Ti O2 rutile nanocrystals," Physical Review $B$, vol. 75, 2007.

[37] E. J. Ekoi, A. Gowen, R. Dorrepaal, and D. P. Dowling, "Characterisation of titanium oxide layers using Raman spectroscopy and optical profilometry: influence of oxide properties," Results in Physics, vol. 12, pp. 1574-1585, 2019.

[38] F. Tian, Y. Zhang, J. Zhang, and C. Pan, "Raman spectroscopy: a new approach to measure the percentage of anatase $\mathrm{TiO} 2$ exposed (001) facets," The Journal of Physical Chemistry C, vol. 116, no. 13, pp. 7515-7519, 2012.

[39] C.-N. Huang, J.-S. Bow, Y. Zheng, S.-Y. Chen, N. J. Ho, and P. Shen, "Nonstoichiometric titanium oxides via pulsed laser ablation in water," Nanoscale Research Letters, vol. 5, no. 6, pp. 972-985, 2010.

[40] L. Zhang, Y. Duan, R. Gao et al., "The effect of potential on surface characteristic and corrosion resistance of anodic oxide film formed on commercial pure titanium at the potentiodynamic-aging mode," Materials, vol. 12, no. 3, p. 370, 2019.

[41] P. Zoltowski, "On the electrical capacitance of interfaces exhibiting constant phase element behaviour," Journal of Electroanalytical Chemistry, vol. 443, no. 1, pp. 149-154, 1998.

[42] M. Khadiri, M. Elyaagoubi, A. Elmansouri, A. Benyaïch, and A. Outzourhit, "XPS studies of films formed on the Ti-Cu (2\%) alloy in 5M phosphoric acid," Physical Review B, vol. 71, pp. 76-80, 2014.

[43] S. Kar, High Permittivity Gate Dielectric Materials, Springer, Berlin, Germany, 2013. 